\title{
Ecological Content in Language Teaching Materials of Foreign Speaker in Language Center of Sebelas Maret University
}

\author{
Linggar Dyah Satriyani ${ }^{1}$, Raheni Suhita ${ }^{2}$, and Andayani ${ }^{3}$ \\ ${ }^{123}$ Pascasarjana Universitas Sebelas Maret, Indonesia \\ ${ }^{1}$ linggardyahsatriyani@student.uns.ac.id
}

\begin{abstract}
The mismatched indication of human relations with the natural environment and social environment increasingly disturbing society. Indonesian language learning for foreign speaker should be tucked in with the knowledge about Indonesia, which is could be through by ecological insights. In order to introduce that, it is packaged in the form of teaching materials that is presented through books. Books provide knowledge, improve skills, and a positive attitude to protect and preserve the environment. This research aims to describe and explain the ecological content in teaching material of foreign speaker or as known as BIPA in Language Center of Sebelas Maret University. This research used descriptive qualitative approach by doing content analysis. The method used to collect data is by reading it repeatedly. Data analysis techniques in this research used interactive patterns. The result of this research indicate there are ecological contents in teaching material of foreign speaker in Language Center of Sebelas Maret University: (1) human relations with physic, nature, and ecological environment; (2) involvement with others; (3) engagement with social structures and institutions; (4) community and cultural dependence on time and place; (5) recreational and fun; and (6) simple and relatable.
\end{abstract}

Keywords: Learning Material, Ecology, Foreign Speaker

\section{PENDAHULUAN}

Belakangan ini, gejala tidak serasinya hubungan manusia dengan lingkungan alam maupun lingkungan sosial semakin meresahkan masyarakat [1]. Terjadinya berbagai peristiwa tersebut mengakibatkan perubahan sikap manusia terhadap lingkungan atau ekologi saat ini. Permasalahan manusia terhadap lingkungan yang kompleks tersebut perlu diselesaikan dengan berbagai pendekatan [2]. Suatu pendidikan apabila mengutamakan pentingnya menjaga lingkungan alam sekitar sebagai sumber hidup manusia banyak ditemukan oleh ahli dan pendidik dari abad ke-19 [3]. Ekologi sendiri dikenal oleh masyarakat dunia sekitar tahun 1866 oleh seorang ahli bernama Ernst Haeckel [4]. Istilah Ekologi (Oekologie) dalam bahasa Yunani yakni oikos dan logos. Dari istilah tersebut, ekologi berarti ilmu tentang hubungan yang terjadi antara makhluk hidup dengan lingkungannya secara timbal balik, antara organisme dan lingkungannya. Ekologi tidak hanya membahasa mengenai hubungan manusia dengan lingkungan, melainkan seluruh organisme yang ada di seluruh ekosistem. Ekologi merupakan ilmu yang membahasa mengenai aktivitas makhluk hidup dan hubungannya serta lingkungannya secara keseluruhan sesuai dengan ruang lingkup masing-masing [5]. 
Menurut Undang-Undang Nomor 32 Tahun 2009 terkait dengan "Perlindungan dan Pengelolaan Lingkungan Hidup" dijelaskan bahwa pada bab X bagian 3 pasal 69 tentang larangan mencemari, mencampurkan benda berbahaya dan beracun (B3), memasukkan limbah ke media di lingkungan hidup, melakukan buka lahan dengan cara membakar, dan lainnya [6]. Peraturan tersebut semakin menegaskan bahwa mahasiswa asing yang tinggal di Indonesia juga bertanggung jawab untuk menjaga dan melestarikan lingkungan. Pemerintahan Indonesia melalui Badan Bahasa, menyediakan program BIPA (Bahasa Indonesia bagi Penutur Asing) yang hingga kini masih berjalan. BIPA yaitu sebuah program pengajaran bahasa Indonesia yang ditujukan khusus untuk penutur bahasa kedua (asing), mereka memperoleh materi ajar yang berbeda-beda [7]. Penutur yang dimaksud adalah penutur yang berkebangsaan nonIndonesia dan berbahasa ibu bukan bahasa Indonesia. Pembelajar BIPA biasanya dikategorikan sebagai pembelajar yang memiliki latar budaya yang berbeda daripada pembelajar asli Indonesia, terutama dengan budaya bahasa yang dipelajari mahasiswamahasiswa tersebut [8]. Hal itu untuk beradaptasi di lingkungan yang semakin multikultural dan multibahasa [9].

Perbedaan budaya tersebut melahirkan kebiasaan-kebiasaan baru. Kebiasaan masyarakat sosial yang ramah terhadap lingkungan nantinya akan mewujudkan sebuah tradisi, ritual, simbol-simbol, dan nilai-nilai kehidupan yang berkembang di masyarakat. Sebuah transformasi yang membutuhkan jalan panjang penyadaran, komitmen, konsisten, serta perjuangan yang tinggi untuk membangun kesadaran pentingnya menjaga lingkungan hidup dimanapun kita berada [10]. Bagi mahasiswa BIPA, proses transformasi tersebut bisa terjadi di lingkungan pendidikan. Lingkungan yang mengenalkan berbagai nilai di lingkungan belajar mereka. Karakteristik kurikulum Pendidikan Lingkungan Hidup yang disampaikan oleh kementerian antara lain: (1) muatan lokal kurikulum pendidikan, lingkungan hidup; (2) adanya pembauran atau integrasi dengan seluruh pembelajaran; (3) aplikatif atau bisa diterapkan di kehidupan sehari-hari; (4) bersifat rekreasi serta menyenangkan; (5) berawal dengan hal yang sederhana dan dekat dengan kehidupan siswa [6].

Pembelajaran bahasa Indonesia untuk pembelajar asing atau mahasiswa BIPA sebaiknya juga diselipkan dengan diajrakannya ilmu dan pengetahuan tentang suatu karakter, ciri, atau jati diri bangsa Indonesia, baik secara langsung atau tidak langsung [11]. Brown mengungkapkan bahwa pembelajaran bahasa kedua (asing) yang paling baik yaitu pembelajaran yang pada konteksnya dan komunikasinya bermakna atau praktik secara langsung [12]. Melalui praktik langsung, terlihat ketertarikan mereka akan alam Indonesia yang indah dan keinginan berwisata. Hal tersebut menunjukkan bahwa nilai-nilai cinta lingkungan atau alam kepada mahasiswa BIPA juga bisa diwujudkan melalui pengajaran bahasa Indonesia. Mengenalkan lingkungan alam Indonesia tersebut, dikemas dalam bentuk materi ajar yang disajikan melalui buku. Buku merupakan salah satu sumber belajar sekaligus faktor penting. Buku mampu memberikan suatu pengetahuan, meningkatkan keterampilan, maupun sikap positif terhadap kewajiban untuk menjaga serta melestarikan suatu lingkungan. Buku yang berlandaskan akan nilai cinta lingkungan alam dan lingkungan sekitarnya, mampu menuntun pembaca untuk memiliki inteligensi ekologis (ecological intelligence), yakni menjadikan pembaca sebagai pusat kendali terhadap lingkungan (human as in control of the natural environment) [13].

Ernest Bloch menyatakan bahwa manusia memiliki berbagai pengalaman yang berkaitan dengan lingkungan yang disebut dengan rangkaian anthropological constant, yang berarti sorongan-sorangan dan pandangan tetap manusia. Terdapat enam anthropological constants yang memungkinkan untuk diperoleh melalui sejarah pengalaman hidup manusia, yakni: (1) Relasi atau hubungan manusia maupun jasmani, alam, sekaligus lingkungan ekologi; (2) 
Keterkaitannya dengan yang lain atau sesama; (3) Terikat terhadap struktur sosial kemasyarakatan sekaligus lembaga atau institusi; (4) Bergantungnya manusia serta budaya pada waktu dan tempat; (5) Hubungan yang saling terjadi secara timbal balik antara teori dan praksis; (6) Kesadaran akan religiusitas atau parareligius [14]. Penelitian-penelitian sebelumnya lebih menekankan pada aspek budaya dan aspek lainnya dalam pembelajaran BIPA [11] [15]. Sedangkan penelitian-penelitian lain menerapkan nilai-nilai ekologi pada pembelajaran mahasiswa Indonesia (bukan BIPA)[16][17][18]. Berdasarkan uraian di atas, penelitian ini berttujuan untuk bisa melengkapi penelitian-penelitian sebelumnya dan berfokus pada aspek ekologi atau wawasan lingkungan pada materi ajar kelas BIPA Level 3 di UPT Bahasa Universitas Sebelas Maret.

\section{METODE}

Penelitian ini termasuk dalam jenis penelitian kualitatif deskriptif. Sumber data yang dipilih dari penelitian ini yaitu buku "KEREN" yang digunakan pengajar untuk mahasiswa penutur asing atau BIPA di UPT Bahasa Universitas Sebelas Maret. Subjek penelitian ini dipilih melalui teknik purposive sampling, yaitu melakukan pengambilan data melalui pertimbangan tertentu. Penelitian berikut ini menggunakan model analisis isi (content analysis). Uji validitas data dalam penelitian ini menerapkan uji triangulasi teori. Teknik analisis data yang diterapkan dalam penelitian ini adalah teknik analisis dengan model interaktif. Analisis model interaktif ini merupakan sebuah teknik analisis yang memiliki beberapa langkah penelitian, yaitu: mengumpulkan data, reduksi atau pengurangan data, menyajikan data, dan terakhir menarik kesimpulan [19].

\section{HASIL PENELITIAN DAN PEMBAHASAN}

Materi ajar pada buku "KEREN" untuk mahasiswa penutur asing atau BIPA di UPT Bahasa Universitas Sebelas Maret memiliki berbagai jenis tema yang tersebar di setiap pokok bahasan. Nilai wawasan lingkungan menjadi salah satu tema yang tersurat dan tersirat dalam buku "KEREN" yang menjadi sumber materi ajar bagi para pendidik mahasiswa penutur asing atau BIPA di UPT Bahasa Universitas Sebelas Maret. Sejalan dengan pendapat dari Ernest Bloch [14] dan peraturan dari Kementerian Lingkungan Hidup [6], terdapat beberapa hal termasuk dalam kategori materi ajar berwawasan ekologi atau lingkungan. Hal tersebut meliputi: (1) relasi atau hubungan manusia dengan jasmani, alam, sekaligus lingkungan ekologi; (2) keterkaitannya dengan yang lain atau sesamanya; (3) terikat dengan sebuah struktur sosial kemasyarakatan dan juga lembaga atau institusi; (4) bergantungnya masyarakat serta budaya pada waktu dan tempat; (5) bersifat rekreasi dan menyenangkan; dan (6) berawal dari sederhana dan dekat dengan siswa.

Relasi atau hubungan manusia dengan jasmani, alam, dan lingkungan ekologi pada buku ini tercantum pada bagian 5.16 dengan judul Pasar Ngasem. Sesuai dengan pernyataan Ernest Bloch [14], bagian ini menceritakan hubungan antara manusia dan aspek lain seperti jasmani (raga) dan juga lingkungan tempat tinggalnya. Bacaan mengenai situasi dan kondisi di pasar tradisional Yogyakarta. Teks bacaan menunjukkan bahwa kondisi pasar tersebut kurang bersih. Hubungan antara jasmani dan lingkungan ekologi (pasar) pada teks bacaan ini merupakan bagian dari materi ajar yang berwawasan lingkungan. Materi ajar berwawasan lingkungan berikutnya yaitu mengenai kartu pos, keterampilan menulis yang diitregasikan dengan lingkungan alam. Gambar-gambar yang disajikan merupakan gambar-gambar yang menunjukkan keindahan lingkungan alam Indonesia. Melalui deskripsi gambar tersebut, 
mahasiswa akan lebih mengenal sistem irigasi, menanam padi, membajak sawah, dan lainnya. Contoh yang kedua tersebut merupakan hubungan langsung antara manusia yang terintregasikan dengan jasmani dan lingkungan dalam bentuk kartu pos.

Keterlibatan dengan sesama pada materi ajar ini ditunjukkan dengan gotong royong dan kerja sama. Gotong royong dan kerja sama adalah salah satu ciri masyarakat Indonesia yang khas dan masih diterapkan hingga kini. Bentuk gotong royong pada materi ajar ini ditunjukkan saat panen padi dan memandikan kerbau di sawah. Panen padi merupakan kegiatan yang tidak bisa dilakukan sendiri, perlu kerja sama masyarakat untuk bisa menyelesaikannya. Gotong royong dan kerja sama dalam menjaga dan memanfaatkan lingkungan alam adalah suatu hal yang seharusnya dilakukan oleh manusia, baik itu di kota maupun di desa. Pada materi ajar ini juga terdapat sebuah ilustrasi dialog antar tokoh. Ilustrasi tersebut menunjukkan terdapat seorang anak yang akan memandikan kerbaunya di sungai. Tokoh-tokoh lain menawarkan bantuan untuk memandikan kerbau tersebut secara bersama-sama. Keterlibatan manusia dengan sesamanya merupakan salah satu aspek yang menunjukkan adanya nilai-nilai ekologis atau lingkungan dalam materi ajar ini.

Keterikatan dengan struktur sosial dan institusi pada buku materi ajar kelas BIPA ini masih menerapkan nilai-nilai tradisionalisme di Indonesia. Hal tersebut dibuktikan dengan ilustrasi yang dipaparkan untuk mendukung mahasiswa BIPA mendeskripsikan lingkungan rumah. Lingkungan rumah yang dideskripsikan dari gambar menunjukkan bahwa masyarakat Indonesia masih memanfaatkan sungai untuk menunjang kehidupan sehari-harinya, seperti mandi dan cuci kakus. Selain itu, ilustrasi juga menunjukkan bahwa masyarakat Indonesia masih memanfaatkan lingkungan hutan untuk memasak. Kayu bakar dan tungku masih digunakan sebagai pengganti kompor minyak atau kompor gas. Pengondisi udara maupun lemari pendingin juga tidak ada dalam ilustrasi yang dipaparkan. Struktur sosial kemasyarakatan tertentu juga berpengaruh pada nilai-nilai lingkungan yang ada di masyarakat [14]. Materi ajar ini dipaparkan tradisionalisme masyarakat Indonesia yang masih ada di daerah-daerah tertentu.

Bergantungnya masyarakat dan budayaan akan waktu dan tempat juga ditunjukkan pada materi ajar BIPA ini. Selain memaparkan kondisi lingkungan alam, materi ajar ini juga sekaligus memaparkan kondisi budaya dalam waktu dan tempat tertentu [14]. Hal tersebut ditunjukkan oleh ilustrasi seorang anak kecil yang sedang menghalau burung-burung pemakan padi di sawah. Aktivitas menjaga sawah tersebut merupakan integrasi antara lingkungan alam dan budaya yang tumbuh berkembang di Indonesia. Bentuk pembauran yang diajarkan untuk menjaga lingkungan yang kita miliki dari pihak-pihak yang mengganggu kelestariannya. Di daerah tertentu, menjaga sawah dan menghalau burung menjadi sebuah tradisi yang melekat dan membudaya. Waktu dan tempat pada budaya ini juga menjadi ciri khas Indonesia, karena penen padi hanya bisa dilaksanakan di waktu tertentu setiap tahunnya.

Bersifat rekreasi dan menyenangkan, merupakan salah satu kategori pembelajran yang mengusung pendidikan berwawasan lingkungan [6]. Pada mahasiswa kelas BIPA ini, materi ajar yang bersifat rekreasi dan menyenangkan dipaparkan melalui ilustrasi perjalanan tokohtokoh ke tempat wisata, pedesaan, dan yang lainnya. Secara tidak langsung, mahasiswa dikenalkan lingkungan alam dan pentingnya menghargai lingkungan yang kita tinggali. Kisahkisah perjalanan atau wisata yang terdapat pada materi ajar ini juga mengenalkan kepada para mahasiswa BIPA (Bahasa Indonesia bagi Penutur Asing) mengenai keindahan lingkungan alam. Lingkungan alam yang indah bisa dijadikan daerah tujuan wisata bagi wisatawan domestik maupun asing. Apabila lingkungan kotor dan tidak terawat, maka daerah tersebut juga tidak akan menjadi destinasi wisata yang baik. Contoh lain juga dipaparkan pada bagian 7.1 mengenai perjalanan ke Keraton Sultan. Wisatawan asing memilih untuk mengendarai 
becak daripada alat transportasi modern lainnya. Hal tersebut juga sangat berengaruh terhadap lingkungan karena juga turut mengurangi polusi udara, polusi suara, dan kemacetan daerah wisata.

Materi ajar harus berawal dari hal sederhana dan dekat dengan siswa agar mudah dipahami [6] [20]. Hal sederhana yang dipaparkan pada bagian ini ditunjukkan pada materi 6.16 mengenai alat transportasi. Alat transportasi merupakan suatu hal yang dekat dengan siswa. Ilustrasi menunjukkan transportasi tradisonal yang ada di pedesaan, yaitu gerobak sapi. Gerobak sapi merupakan alat transportasi tradisional yang digunakan untuk mengangkat beban berat dalam jarak dekat. Materi mengenai alat tradisional ini mengenalkan kepada mahasiswa asing tentang pentingnya mencintai lingkungan dengan cara mengurangi polusi dari alat transportasi mesin atau modern. Selain itu, contoh lain yang dipaparkan pada materi ajar ini adalah penggunaan transportasi umum. Transportasi umum sebuah sarana untuk mempermudah kehidupan manusia yang memiliki banyak manfaat. Alat transportasi ini membantu mengurangi polusi udara dan juga kemacetan lalu lintas. Pada kutipan dialog tersebut, tokoh juga mengatakan bahwa kendaraan umum dipilih karena jarak yang ditempuh tidak terlalu jauh. Nilai-nilai wawasan lingkungan pada materi ajar ini disampaikan dengan cara sederhana dan dekat dengan siswa.

\section{SIMPULAN}

Secara umum, materi ajar kelas BIPA di UPT Bahasa Sebelas Maret mengandung wawasan lingkungan. Wawasan lingkungan pada materi ajar tersebut tersebar di beberapa topik, seperti mendengarkan, berbicara, membaca, dan menulis. Hal tersebut dibuktikan dengan adanya aspek-aspek relasi atau hubungan manusia dengan jasmani, alam, dan lingkungan ekologi. Bagian ini ditunjukkan dengan adanya bacaan mengenai pasar tradisional dan juga penggunaan kartu pos dengan gambar lingkungan alam untuk mengirimkan surat sebagi bentuk interaksi jasmani. Keterlibatan dengan sesama pada bagian ini ditunjukkan dengan adanya bacaan mengenai gotong royong dan kerja sama saat memanen padi dan memandikan kerbau di sungai. Ilustrasi menunjukkan baha kegiatan tersebut dilakukan secara bersama-sama. Kemudian, keterikatan dengan struktur sosial kemasyarakatan dan institusi atau lembaga ditunjukkan dengan adanya ilustrasi rumah di Indonesia yang masih mengangkat tradisionalisme. Hal tersebut terbukti dengan adanya gambar peralatan rumah tangga yang berasal dari alam. Materi ajar ini juga menunjukkan bahwa masyarakat serta budaya bergantung akan waktu dan tempat. Bagian ini ditunjukkan dengan ilustrasi aktivitas seorang anak yang sedang menunggu sawah dan menghalau burung. Suatu kebiasaan yang menjadi budaya pada waktu tertentu (saat musim panen saja). Suatu materi ajar yang digunakan juga memiliki sifat rekreasi dan menyenangkan. Bagian ini ditunjukkan dengan adanya ilustrasi pariwasata ke lingkungan pedesaan. Bentuk ilustrasi rekreasi pada materi ajar menunjukkan bahwa mengenal lingkungan juga bisa dilakukan secara menyenangkan. Terakhir, berawal dengan cara sederhana dan dekat dengan siswa. Bagian ini menunjukkan bahwa materi yang berwawasan lingkungan dikenalkan melalui hal sederhana dan dekat dengan kehidupan seharihari, seperti penggunaan alat transportasi. Jadi, dapat disimpulkan bahwa materi ajar berwawasan lingkungan ditemukan dan digunakan dalam pembelajaran bahasa bagi mahasiswa BIPA di Universitas Sebelas Maret.

\section{REFERENCES}

[1] A. M. Mbete, "Pembelajaran Bahasa Berbasis Lingkungan : Perspek- Tif Ekolinguistik," 
vol. 1, no. 2, pp. 352-364, 2015.

[2] R. Mathar, "A Whole School Approach to Sustainable Development: Elements of Education for Sustainable Development and Students' Competencies for Sustainable Development," In Schooling for Sustainable Development in Europe: Concepts, Policies and Educational Experiences at the End of the UN Decade of Education for Sustainable Development, 2015.

[3] N. B. Segera, "Education for Sustainable Development (ESD) Sebuah Upaya Mewujudkan Kelestarian Lingkungan," SOSIO Didakt. Soc. Sci. Educ. J., 2015.

[4] G. Tsvetin Trifonov, "Endoscopic Extraperitoneal Transvesicocapsular Adenomectomy of Prostate (EETAP): A New Operative Method with an Innovative Learning Protocol for Its Performance," in Prostatectomy, 2019.

[5] F. E. Manusia, "Perkaitan Antara Faktor Sosioekonomi dan Kualiti Tingkahlaku Keibubapaan dalam Keluarga Berisiko Zarinah Arshat Rozumah Baharudin," J. Kemanus. bil.17, Jun 2011 Perkaitan, 2011.

[6] U. R. Indonesia, Perlindungan dan Pengelolaan Lingkungan Hidup. 2009.

[7] I. Suyitno, "Pengembangan Bahan Ajar Bahasa Indonesia untuk Penutur Asing (BIPA) berdasarkan Hasil Analisis Kebutuhan Belajar,” Wacana, J. Humanit. Indones., 2007.

[8] E. Inderasari and T. Agustina, "Pembelajaran Bahasa Indonesia Pada Mahasiswa Asing dalam Program BIPA Iain Surakarta,” J. Pendidik. Bhs. dan Sastra Indones., 2017.

[9] C. Kramsch, "Ecological Perspectives on Foreign Language Education," Lang. Teach., 2008.

[10] M. Ahmad, "Pendidikan Lingkungan Hidup dan Masa Depan Ekologi Manusia," FORUM Tarb. Vol. 8, No. 1, Juni 2010, vol. 8, pp. 57-71, 2010.

[11] Ulumuddin Arisul dan Wismanto Agus, "Bahan Ajar Bahasa Indonesia Ranah Sosial Budaya Bagi Penutur Asing (BIPA),” J. sasindo, 2014.

[12] A. Kusmiatun, "Topik Pilihan Mahasiswa Tiongkok dalam Pembelajaran BIPA Program Transfer Kredit di UNY," LITERA, 2016.

[13] R. Utina, "Kecerdasan Ekologis dalam Kearifan Lokal Masyarakat Bajo Desa Torosiaje Provinsi Gorontalo," Pros. Konf. dan Semin. Nas. Pus. Stud. Lingkung. Hidup Indones. ke 21, 2012.

[14] K. Kaswadi, "Paradigma Ekologi dalam Kajian Sastra,” Paramasastra, 2015.

[15] E. Subali, "Konsep Bilingualisme dan Pembelajaran Bahasa Indonesia Bagi Penutur Asing," J. Sos. Hum., 2015.

[16] N. Kholis and R. Karimah, "Aksi Budaya Teo-Ekologi Melalui Integrasi Kurikulum Pendidikan Lingkungan Hidup," Al-Tahrir J. Pemikir. Islam, 2017.

[17] "Pengembangan Bahan Ajar Ekologi Kurikulum 2013 Bermuatan Sets Melalui Penerapan Model Problem Based Learning," 2016.

[18] M. M. Solichin, "Pendidikan Agama Islam Bewawasan Spiritualitas Ekologi: Telaah Materi Dan Model Pembelajaran," Al-Tahrir J. Pemikir. Islam, 2017.

[19] P. D. Sugiyono, metode penelitian kuantitatif, kualitatif,dan R\&D. 2016.

[20] K. Saddhono, "Integrating culture in Indonesian language learning for foreign speakers at Indonesian universities,” J. Lang. Lit., vol. 6, no. 2, 2015. 